\title{
ACTABILITY: A WAY TO UNDERSTAND INFORMATION SYSTEMS PRAGMATICS
}

\author{
Göran Goldkuhl ${ }^{1,2}$, Pär J. Ågerfalk ${ }^{3,1}$ \\ ggo@ida.liu.se,pak@esa.oru.se \\ ${ }^{1}$ Centre for studies on Humans, Technology and Organization (CMTO) and \\ Dept. of Computer and Information Science (IDA) \\ Linköping University, SE-581 82 Linköping, Sweden \\ ${ }^{2}$ Jönköping International Business School, P.O. 1026, \\ SE-551 11 Jönköping, Sweden \\ ${ }^{3}$ Dept. of Informatics (ESA), Örebro University \\ SE-701 82 Örebro, Sweden
}

\begin{abstract}
This chapter addresses the issue of understanding the pragmatics of information systems. Such understanding is important in order to realize the organizational role of information technology and to design information systems that meet the true requirements of their users. The concept of actability is argued as the preferable conceptualization of information system usage if pragmatic aspects and their business implications are to be considered. The chapter presents a general model of social action and relates it to the socalled semiotic ladder. The model is then used to characterize information systems as artefacts used for organizational action. Building on that characterization, information systems usage in terms of supporting human action is analysed within the concept of actability. Finally, some implications for the design of information systems are discussed. The main message of the chapter is that information systems should be conceived as, and consequently designed to be, systems intended for action.
\end{abstract}

Keywords: actability, pragmatics, action, artefact.

\section{Introduction}

The many failures of IT-based information systems give rise to a strong imperative for researchers in information systems and neighbour disciplines to create a better understanding of the nature of such systems and their organizational use. Just viewing an information system (IS) as a technical black box having some social and organizational effects is not enough. We must understand information systems in a deeper sense than as just one kind of technical artefact. What special kind of artefact is an information system?

The semiotic perspective offers great possibilities for such a deeper understanding (Stamper, 1994; 2000). Starting from the notion of sign, we can focus on different aspects of information systems as sign systems, ranging from pure technical to social and organizational issues. In classical semiotics, three levels (or aspects) are distinguished: syntactics, semantics and pragmatics. Stamper (ibid.) adds some more levels and constructs a 'semiotic ladder', with the following steps from bottom to top: physical world, empirics, syntactics, semantics, pragmatics and social world.

The pragmatic dimension of human communication has been studied and conceptualized within speech act theory (Austin, 1962; Searle, 1969; Habermas, 1984). A 'language action' perspective on 
information systems has been articulated by several scholars, taking their main inspiration from speech act theory (e.g., Winograd \& Flores, 1986; Goldkuhl \& Lyytinen, 1982; Dietz, 1994). The fundamental speech act thesis is that communication is to be seen as one kind of action. Searle (1969) distinguishes between four different sub-acts of a speech act:

- Utterance act

- Propositional act

- Illocutionary act

- Perlocutionary act

The utterance act is to be seen as the production of a sequence of words that together form a comprehensible wholeness of an utterance. We understand this mainly as equivalent to the syntactic level. The propositional act means referring and predicating, i.e., representing a world talked about in an utterance. This corresponds to the semantic level. The illocutionary act is what we are doing by speaking, for example, stating, commanding, promising or declaring. The perlocutionary act is the intentional 'causing' of effects in listeners. The relationships between these two last sub-acts and the semiotic aspects are not straightforward. We will discuss these matters in Section 2 below.

To distinguish between utterance, proposition, illocution and perlocution seems to be important. We think, however, it is misleading to describe these as different sub-acts performed within a speech act. They are rather different aspects of a speech act. We introduce these notions here as we will use them later in the chapter.

A pragmatic perspective on information systems seems to offer good possibilities for a deeper understanding of such systems as artefacts in organizational settings. The purpose of this chapter is to explore the pragmatic character of information systems. Taking the semiotic ladder as our point of departure we eventually arrive at the concept of information systems actability, which we define as an information system's ability to perform actions, and to permit, promote and facilitate the performance of actions by users, both through the system and based on information from the system, in some business context. In conducting the journey, we investigate possible meanings of pragmatics related to information systems and touch upon some implications for information systems design.

The chapter is structured as follows. In Section 2 we discuss different interpretations of information systems pragmatics starting from the semiotic ladder. In Section 3 we relate information systems to concepts of action, organization and artefact. A generic action model is presented as a basis for the actability concept. The key concept of this chapter, information systems actability, is thoroughly discussed in Section 4 and some implications for information systems design are presented in Section 5. Finally, conclusions of the chapter are presented in Section 6.

\section{Information Systems and Pragmatics}

Stamper (1994; 2000) presents a semiotic ladder for analysing different aspects of information systems as sign systems. This Organizational Semiotics approach to information systems has had a substantial influence on the IS field and several authors have adhered, and contributed, to it (cf. Liu et al., 2000). The semiotic ladder consists of the following steps: physical world, empirics, syntactics, semantics, pragmatics and social world. The pragmatic level is defined in the following way (ibid.): 'Pragmatics is the branch of semiotics concerned with the relationships between signs (as meaningful utterances) and the behaviour of responsible agents, in a social context.'

The relationship between action (i.e., 'behaviour of responsible agents') and signs is, however, not unambiguous. It is possible to identify different relationships. We use Figure 1 to illustrate our reasoning. 
A message (depicted in Figure 1) can be produced by a human agent or an IS. This message (a sign constellation) is received and interpreted by some human agent. After interpreting the message, the agent performs some action based on that interpretation. The common understanding of the pragmatic aspect of information systems seems to be this kind of 'ex post action', i.e., an action based on messages from an IS (e.g., Langefors, 1995). The pragmatic aspect of information systems is concerned with the actions performed by humans after receiving messages from information systems. In what ways are humans influenced by messages from information systems? What are humans doing when using messages from information systems as a base? This is one interpretation of pragmatics, but not the only one.

Let us look more closely at the message, which can be produced by an IS or a human. Is such a message not the result of an action? Yes, it should be seen to be an action result. We must, thus, add another pragmatic dimension to the one described above: the message as a result of an action. The production of this message is to be considered as an action. What else would it be? This is obvious if the producer of the message is a human agent. In this case, the situation is a human-to-human communication. Speaking and writing is action (Austin, 1962; Searle, 1969). Even when the producer is an IT artefact, the production of the message must be a communicative action. This might perhaps be harder to accept, but we will elaborate on this below (Section 3). This thesis is vindicated in the language action tradition of information systems (e.g., Goldkuhl \& Lyytinen, 1982).

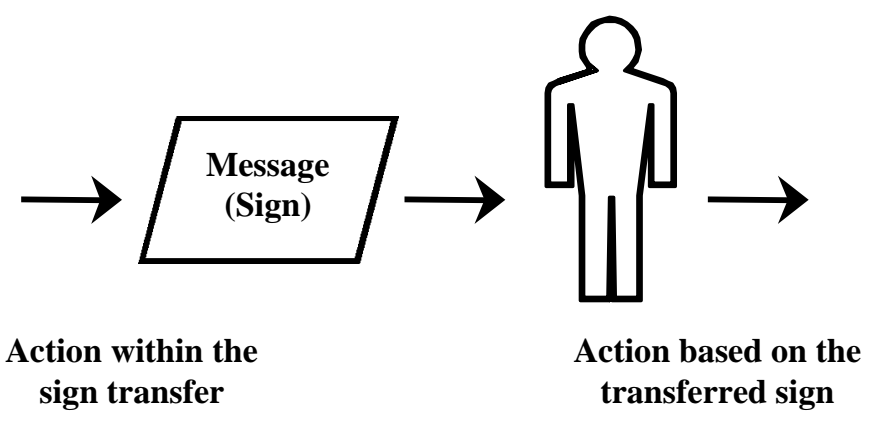

Figure 1: Different kinds of actions related to signs.

The sign transfer (i.e., a communication process) is an action, according to our definition. The action within the sign transfer should be seen as a pragmatic aspect. This means that the information system's production of messages to its environment should also be seen as an action. Pragmatics is not only related to actions based on messages from information systems. The very production of messages (signs) also has a pragmatic dimension, since this sign production should be considered as action.

The sign transfer as action is, with reference to concepts of speech act theory (Austin, 1962; Searle, 1969), considered to be a so-called illocutionary act. This is what is done in speaking. Actions based on the communicated sign are considered to be on the perlocutionary level. In speech act theory, this relates to effects arising from communication: what the listener does covertly or overtly.

These two aspects are important pragmatic aspects of information systems:

- action within the sign transfer

- action based on the transferred sign

These two aspects should be both acknowledged and distinguished, as they can be by aid of the speech act notions of illocution and perlocution. As can be seen from Figure 1, they are related. We will 
elaborate this further. The sign as action might give rise to expectations in the interpreter. These expectations are intrinsically tied to the illocution performed. The sign is a base for action and this action can be seen as fulfilment or rejection of the expectations as well as other perlocutionary effects. When a person A asks a person B 'Would you bring me a glass of water?', A performs a request directed towards $\mathrm{B}$. This request action (which is a special kind of illocution) gives rise to expectations directed from A to B. A expects B to perform an action of bringing water. B can react in different ways, declining the request or fetching a glass of water. Refusal or delivery is action in response to the request. These different types of actions are considered as perlocutionary effects of the speech act of the request. The delivery of the water is the effect intended by A.

In our conception of information systems pragmatics, we include the two action aspects described above. Stamper (1994) treated these two aspects within his semiotic theory. In Stamper's semiotic ladder the illocutionary aspect seems mostly to be related to the pragmatic level ${ }^{1}$ and the perlocutionary aspect seems mostly to be related to the social level ${ }^{2}$. In our framework it is not possible to make these kinds of characterizations. The two types of action (action within sign transfer, action based on transferred sign) are both actions and as such they of course involve a pragmatic dimension. We claim that these two kinds of action involve a social dimension also.

The sign transfer action is a social action since its main purpose is to create a shared understanding between human beings (Habermas, 1984). Different interpersonal relationships are established because of the actual illocution performed. The action based on the transferred sign is also to be seen as a social action. This is the case even if the listener does not explicitly respond to the 'initial' speaker overtly. Even if the listener performs an action (based on the transferred sign) in isolation, we call this a social action since the user directs the action in relation to other humans. This seems to be in accordance with Weber's (1978) classical definition of a social action.

Pragmatics is about action. When we talk about intentionally arranged signs related to action, it seems impossible to exclude a social dimension. The actions of the two kinds are social actions. In our opinion, it is hard to distinguish between the social and pragmatic stages on the semiotic ladder concerning these types of actions. Producing signs requires actions and such actions are in most cases social actions.

\section{Information Systems: Action Artefacts in Organizations}

\subsection{Human action}

Human action is about making a difference. This is one fundamental thesis of the American pragmatists (Thayer, 1981). Humans intervene in their outside world and create differences. Human action often aims at making material changes. Chopping wood means that wood is transformed into firewood, which later can be put into a fire to create heat. Action is meaningful and intentional. Humans act in order to achieve ends.

The world of humans is not only a material world. It is also a social world consisting of other humans and their expressions. Communicating is also action (Austin, 1962; Searle, 1969). To utter a sentence, directed towards another human being, is one kind of action. There are differences and similarities

\footnotetext{
${ }^{1}$ Stamper (1994) explicitly relates the pragmatic level to the illocutionary level: 'It is also possible to model some aspects of intentional sign use in terms of speech act theory by studying so-called illocutionary verbs'.

${ }^{2}$ When describing the social level, Stamper (1994) makes an explicit reference to the perlocutionary level: 'Each illocutionary act will have a social consequence achieved by the listener(s) performing (a) perlocutionary act(s), which change(s) the social world.' (ibid.).
} 
between communicative and material acts. It is, however, possible to use a generic action model $^{3}$ to describe both kinds of action (Figure 2).

We distinguish between the following categories:

- Action prerequisites (external and internal)

- Actor (interventionist)

- Acting (performance of action)

- Action result (what is done)

- Receiving (interpreting) action result

- Actor (recipient)

- Effects of action

- Relationships between actors

- Action context (place and time)

We use two examples to describe the generic model. (1) A communicative act of a woman asking her husband to bring in some firewood: 'Would you please bring some firewood in. I think it is cold in here'. (2) A material act of chopping wood performed by the husband.

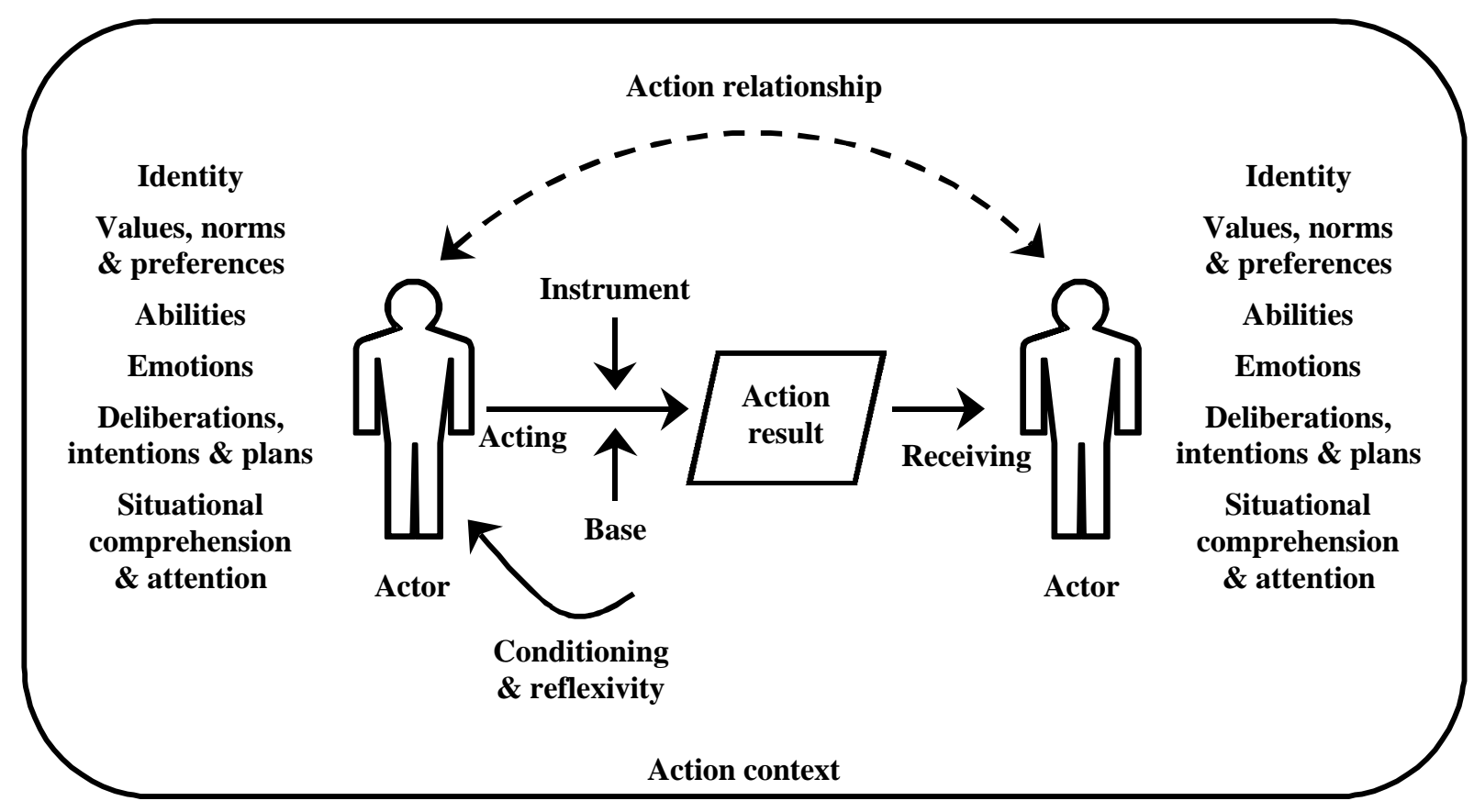

Figure 2: A generic model of social action.

We use the different action categories described above and in Figure 2 to characterize the two kinds of actions (see Table 1 for an overview). This does not mean that there are not important and fundamental differences between communicative and material actions. There are important differences, which will be shown. In communication we transform our own knowledge (as the base) into a linguistic utterance (the result). When doing so we are using language as an instrument. Language must be inter-subjective to a large degree, otherwise the communication will not be successful, i.e., no shared understanding will arise. In material action an external base (such as wood) is transformed into a material result (such as

\footnotetext{
${ }^{3}$ This generic action model emanates from earlier work (Goldkuhl, 1998ab; Goldkuhl \& Röstlinger, 1999).
} 
chopped firewood). The actor is using an external instrument (such as an axe) to produce results. The utilization of such an instrument (tool) extends the capabilities of the actor. The actor will have different relations towards the different external objects. He or she will have a transformative relation towards the base, a utilizing relation towards the instrument and a producing relation towards the result. Base, instrument and result are thus important categories for describing action. The base is transformed to a result by a competent utilization of an instrument. In the example, there is an oral face-to-face communicative action; and in such a situation there is no use of an external instrument. When speaking to a person at some distance we usually require some instrument, often a telephone, to bridge the distance. Written communication implies the use of external instruments, such as a pen or typing equipment.

Base and instrument are two fundamental prerequisites for action. In the case of material action, these prerequisites are external objects. In the case of communicative action, these prerequisites are internal elements, i.e., parts of the practical consciousness of the actor. There are other internal prerequisites, both situational and trans-situational. We claim that actions are purposive, i.e., there are intentions associated with the actions. We do not, however, claim that intentions are always well defined and deliberate before the performance of the action. Intentions can arise from situations (Joas, 1993). Ends and means can be figured out when interacting with the environment. This implies that the situational understanding and the attention of the actor are fundamental for acting (ibid.; Giddens, 1984).

\begin{tabular}{|l|l|l|}
\hline Category & Communicative action (request) & Material action (chopping) \\
\hline Interventionist actor & The wife & The husband \\
\hline Intention & To urge the husband to fetch firewood & To fulfil the wife's request \\
\hline Acting & Speaking (request for firewood) & Chopping \\
\hline Base & Knowledge about needs & Wood \\
\hline Instrument & Language & Axe \\
\hline Abilities & Communicative competence & Chopping competence \\
\hline $\begin{array}{l}\text { Situational comprehension \& } \\
\text { attention }\end{array}$ & $\begin{array}{l}\text { Perceiving room temperature and } \\
\text { non-existence of firewood }\end{array}$ & $\begin{array}{l}\text { Continuously monitoring own } \\
\text { chopping }\end{array}$ \\
\hline Result of action & Utterance (request) & Firewood (chopped) \\
\hline Recipient & The husband & \begin{tabular}{l} 
The wife \\
\hline Effects
\end{tabular} \\
$\begin{array}{l}\text { The husband understands and accepts } \\
\text { the wife's request and goes to chop } \\
\text { wood }\end{array}$ & $\begin{array}{l}\text { (1) The wife receives firewood to put } \\
\text { on the fire } \\
\text { (2) Heat from the fire }\end{array}$ \\
\hline
\end{tabular}

Table 1: A comparison between a communicative act and a material act (example).

Following the classical model of social action by Weber (1978), we can add that actions are also governed by values, emotions and traditions (norms). In accordance with the writing of Weber (ibid.), we claim the multifunctionality of action (Goldkuhl, 1998a); i.e., action is often governed by all these prerequisites (purposes, values, emotions and norms), which are expressed during action. The request of the wife is of course purposive, but at the same time it can be seen as compliance to a social norm concerning division of work within this family, namely 'the husband is the one who fetches firewood'. This is also related to the conceived identity of the actors: 'Who am I-what is my role in this situation?' The action prerequisites mentioned by Weber (ibid.) are important, however they are not complete. As can be seen in Figure 2 we add some more important prerequisites.

The two actions described together form a social interaction. Of course, we interact with other people through language, but we also interact by producing and delivering material objects to each other. The material action of the husband is assigned by the request of the wife. The wife's request is self-assigned. 
In the interaction, different action relationships arise between the participants ${ }^{4}$. The request gives rise to expectations directed towards the husband. The delivered firewood may give rise to emotions of gratitude towards the husband.

There is an important difference in the generic action model between action result and action effects. The action result (what is done) is within the range of the actor, i.e., it is within the actor's control. The effects are what can arise as consequences of the action. The speaker has no control over the effects connected to the receiver. The listener can understand the utterance in different ways; e.g., they can misunderstand in ways that the speaker could not presume. The listener can act in ways outside the scope of the speaker's intention. In the communicative act case, the action result reflects the uttered request. The effects of the action are the understanding of the receiver and the consequential actions based on this understanding ${ }^{5}$. The result of the material act is the chopped firewood. The effects are what the wife does when she receives the firewood. The reception of a message (oral or written) implies always an interpretation of what is communicated. Even the reception of material objects implies interpretation: 'What kind of material is this and how can I use it?' Effects of actions may be both social/non-material and material. This applies to both communicative and material actions. The communicative action of the wife - the request — gives rise to both commitments made by the husband and material changes of chopped wood. The material action of delivering firewood to the wife gives rise to social effects (the fulfilment of a performed commitment and the gratitude for this) and material effects (heat from the fire).

This generic model of action can be compared to other models. It is beyond the scope of this chapter to make any thorough comparison to other models ${ }^{6}$. We will, however, briefly compare it to a model by Norman (1988). We do this since we will discuss the actability concept in relation to Norman's model in Section 4 below. Norman (1988) presents a seven-stage model of human action. The main domain for his action model is humans' interaction with everyday things. The seven stages are (1) forming the goal, (2) forming the intention, (3) specifying an action (action sequences), (4) executing the action, (5) perceiving the state of the world, (6) interpreting the state of the world and (7) evaluating the outcome. These seven stages can be divided into three phases: preparation (stages 1-3), execution (stage 4) and evaluation (stages 5-7). Norman speaks only of execution and evaluation, but we think it is also important to distinguish between preparation and execution.

There are some terminological differences between the models. Norman differentiates between the goal and the intention. The differences between these seemingly similar concepts are that goals are to be seen as the ends, and intentions are to be seen as the means. In our action model we distinguish between underlying values and preferences (i.e., more fundamental endeavours and purposes), specific intentions of the action (ends), plans (means for achieving the intentions) and deliberations (which involve considerations concerning both ends and means, i.e., reasons for choosing a certain action and not choosing another one).

Norman's model can be criticized for having a rationalistic flavour: a strict sequence of preparation, execution and evaluation with predefined purposes before entering into acting. In our model we emphasize the continuous perception of the world, i.e., the world is perceived before, during and after

\footnotetext{
${ }^{4}$ Habermas (1984) has contributed to speech act theory by emphasizing that different interpersonal relationships are established between speaker and hearer in communication.

${ }^{5}$ These differences can be related to concepts of speech act theory. Searle (1969) distinguishes sharply between what is done within the utterance (the illocution) and what is intended to be done by the listener (the perlocution). The illocution is one part of the utterance, i.e., what is done by the speaker (the result). Effects related to the listener can be named perlocutionary effects.

${ }^{6}$ Parts of the theoretical background of this action model are described by Goldkuhl (1998a; 1998b) and Goldkuhl \& Röstlinger (1999).
} 
the execution of action. An actor starts from a situational understanding of the action context. This situational understanding determines what ends and means will be chosen ${ }^{7}$. (The wife is thinking 'It is cold in here, but I could make a fire in the fireplace'). During action, the actor is continuously monitoring his or her actions, the results and effects. This constant monitoring makes it sometimes possible to modify an action during its execution. The actor is attentive in action. When chopping wood it is necessary to be attentive otherwise one can cut oneself. This notion of continuos perception is also acknowledged by Norman (ibid.) who states that 'There is a continual feedback loop, in which the results of one activity are used to direct further ones, in which goals lead to subgoals, intentions lead to subintentions. There are activities in which goals are forgotten, discarded, or reformulated.'

We have above described some fundamentals of communicative and material action. Not all human action is of these types, which can be labelled interventionist action (Goldkuhl, 1998b). There are other types of action, such as investigative action and reflective action. These kinds of actions do not aim at external changes, but rather at internal changes of the actor in terms of improved knowledge (ibid.).

\subsection{Organizational action}

Organizations create products (goods or services) beneficial for their environment; i.e., for their customers or clients. In doing this, different actions must be performed. There can be material acts with the purpose of producing material results. There can be communicative acts with the purpose of producing communicative results (utterances and messages). Material acts and communicative acts together form patterns of action. They form not only a language game, but also an 'activity game', with relations between communication and material treatment (Goldkuhl, 1996). Large parts of this activity game are recurrent actions and are thus institutionalized in the organization and the practical consciousness of its participants (Berger \& Luckmann, 1967; Giddens, 1984; Scott, 1995). Some of these actions are internal, i.e., directed towards the interior of the organization. Other acts are external, i.e., directed towards its environment.

When we use the term organizational action, what do we mean by this? Do we mean that the organization acts? Or do we mean that the human members of the organization act? Actually, we use both meanings. We conceive organizations to have action ability (Goldkuhl \& Nilsson, 2000). We say that organizations act. Is this not a reified ${ }^{8}$ position? A view that organizations have been given an ontological status of their own outside the realm of human originators? We do claim that organizations are actors, but they are not actors on their own. They always have a human origin and purpose. Organizations are created by humans and for the purposes of those humans. Organizations act always through their human co-workers or through artefacts arranged by humans. They cannot act by themselves, only through humans (ibid.; Ahrne, 1994).

The co-workers act on behalf of the organization. They act in the name of the organization. An act performed by a human co-worker is always dual. It is an action performed by a human being, but is also at the same time an action performed by the organization. Humans act in organizational roles. Their action is representative. They represent the organization when acting. Given this definition, it is possible to say at the same time that an organization acts and that its human co-workers act.

\footnotetext{
${ }^{7}$ We think it is possible to combine a purposive view of action with a situational view, i.e., that action is both purposive and situationally constrained. Purposes can arise from situations, but can also be brought into situations by deliberate planning.

${ }^{8}$ Berger \& Luckmann (1967) describe the meaning of reification and the problems and dangers of reifying social phenomena, i.e., disregarding the human origin of socially constructed products.
} 


\subsection{The nature of artefacts}

When describing human action above, we pointed out that instruments are often important means for performing actions. To chop wood without an axe is not possible. Humans use artefacts to extend their action ability. Some artefacts improve actions and others even enable certain actions. The modern world is a world crowded with artefacts. They play a dominant role in today's society (Latour, 1992). Many artefacts go even beyond enabling human action. They are created to be independent performers of action. Such artefacts have dynamic properties, which make it possible for them to function on their own. A modern washing machine can work by itself after a human has started it. The washing machine substitutes the washing work otherwise performed by a human being. The axe does not make anything by itself. It is a tool with static properties. Weizenbaum (1976) uses the concepts of prosthetic tools and automatic machines. A prosthetic tool, like an axe, extends the ability of humans. An automatic machine, like a washing machine, has an autonomous ability to function on its own. There are, however, artefacts that do not easily fit into these categories. How about a car? It has abilities to perform work (like moving), but it does not function totally on its own. A human drives a car. A car requires constant manoeuvring. It is a dynamic tool, but a human must operate it.

We divide artefacts into these three categories (Table 2). We will use this classification when discussing information systems based on computers and information technology.

\begin{tabular}{|l|l|l|l|}
\hline & Static tool & Mechanical tool & Automatic machine \\
\hline Way of functioning & Static & Dynamic & Dynamic \\
\hline Degree of dependence & Active use by human & $\begin{array}{l}\text { Active use and } \\
\text { surveillance by human }\end{array}$ & Autonomous \\
\hline Type of action & Human-supported action & $\begin{array}{l}\text { Human-artefact } \\
\text { cooperative action }\end{array}$ & Artefact action \\
\hline Role of humans & Wield & Manoeuvre & Initiate \\
\hline Example & Axe & Car & Washing machine \\
\hline
\end{tabular}

Table 2: Classification of different types of artefacts.

\subsection{IT-based information systems}

IT-based information systems can be used for communicative action or for internal or external organizational actions. The IS actions must be well integrated into the activity games of the organization. This means that an IS, as an artefact, must be congruent to the actions of humans and to the overall objectives of the organization.

We identify three kinds of actions related to information systems: interactive, automatic and consequential actions (Figure 3). A user can utilize an information system to perform certain actions. The IS is used as an action medium for the user to perform actions. In interaction between the user and the computer a communicative action is performed and the results of this action (i.e., a message) is transmitted through the IS. This kind of action — which we call an interactive action-is performed with support by the IS and through the IS.

An IT-based information system is not only used as an interactive mechanical tool, but also as an automatic machine. Usually, a system is provided with an ability to perform certain predefined actions of its own. Based on messages in the system, new messages can be derived and communicated to its environment. These kinds of action are called automatic actions. It is important to state that the computer performs these actions in accordance with well-defined rules created by humans. The responsibility for the actions rests upon those humans who decide the rules to be followed. We mean that it is possible to talk about automatic actions performed by an IT-based information system in this way, without falling into the trap of reification. In this context, reification would mean that we forget 
the human origin of information systems and IS action, that we conceive information systems to be independent actors creating actions totally on their own. We avoid such a reifying position by claiming that information systems perform actions that are predefined to them by human actors. An IS does not find out what kind of actions to perform. The systems' actions derive ultimately from the rules predefined to the system. We do not presuppose computers to have human properties of consciousness and ethical responsibility.

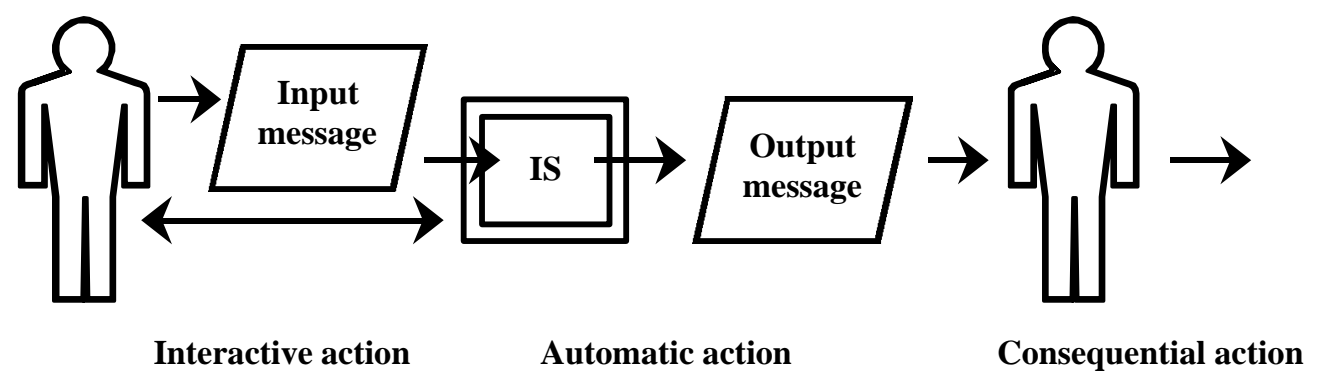

Figure 3: Different actions related to an information system.

Automatic actions of an IS will produce messages (with defined illocutionary and propositional meanings) to its environment, i.e., to some IS users. Such messages can be a basis for actions by these users. We call such user actions consequential actions. These actions can be seen as perlocutionary effects in relation to the communicative actions performed by the IS.

This view of information systems means a rejection of the view of information systems as mere 'containers of facts', as passive providers of information for future actions of human users. Information systems are used for communication among people within and outside the organization. An information system is also an active party in such a communication. It is an artefact with capabilities to perform communicative actions on behalf of the organization (Goldkuhl \& Aggerfalk, 1998). We conceive information systems to be information action systems. An IS should have its own pragmatic properties (i.e., be able to perform communicative actions with illocutionary intent) and not only bring about pragmatic effects (i.e., humans performing actions based on messages from information systems as 'perlocutionary responses'). This view is also reflected in our conceptualization of 'message'.

In traditional information systems theory (e.g., Langefors, 1966), the smallest element of information is the elementary message (the e-message). The basic e-message is a triple $(o, p, t)$ consisting of a reference $o$ to an object in the universe of discourse, a reference $p$ to a property predicated to that object and a reference $t$ to a point in time or a time interval during which the e-message is valid. Similarly, a relational e-message $e=\left(\left(o_{1}, o_{2}, \ldots, o_{\mathrm{n}}\right), r, t\right)$ is used to assign the objects $\left(o_{1}, o_{2}, \ldots, o_{\mathrm{n}}\right)$ to the relation $r$. Goldkuhl (1995) argued that the e-message concept must be extended with an illocutionary component to reflect the illocution of the message. By elaborating this further, we arrive at the concept of action elementary message (ae-message). When we talk about messages as results of communicative actions, we refer to ae-messages. Since an illocution can be (and usually is) associated with a larger propositional content (references and predicates) than a single e-message, an ae-message can be considered as an aggregate of e-messages with an associated action mode representing the illocutionary intention of the ae-message. The key point is that while an e-message is the smallest unit that carries information (or rather propositional content), an ae-message is the smallest unit that carries an action mode. When discussing the pragmatics of information usage in organization, it is meaningless to dissect information down to the level imposed by the e-message concept. However, when it comes to the design of the persistent storage of information (e.g., a database) it is important to understand the relation between ae-messages and e-messages so that 'traditional' approaches can be utilized. It is important, 
though, to not fall into the trap of disrespecting the coupling between the propositional content and the action mode.

Let us consider an example to illustrate the concept of ae-message. Suppose that a virtual bookshop is, via their Web site, offering potential customers a special 'book of the month' to buy for a very special price. This on-line offer is an ae-message sent from the bookshop to potential customers. The action mode of the message is a promise that customers can buy the book at the specified price during the specified month. The propositional content might be data on the book's title, number of pages, author, publisher, price (ordinary and reduced), et cetera. Note that we would require several e-messages to represent this single ae-message's propositional content and that it would not have made sense to try to connect these separately to its action mode. Doing so would have required another relational e-message referencing the first ones. This would have been to treat illocutions as describable pieces of reality (belonging to the object system) rather than as constituents of communicative actions (as parts of the discourse).

\section{The Concept of Information Systems Actability}

Information systems actability (Goldkuhl \& Ågerfalk, 1998; Cronholm et al., 1999; Ågerfalk, 1999) is a conceptualization of the understanding of information systems as tools for organizational action and communication. This is in contrast to the misconception that information systems are used only as passive providers of information to be used for future action, i.e., action based on transferred signs. Actability is an attempt at a synthesis of the usability perspective as applied within the human-computer interaction tradition (e.g., Preece et al., 1994) and the language action perspective (LAP) (e.g., Goldkuhl \& Lyytinen, 1982, Winograd \& Flores, 1986) from an information systems point-of-view.

A central concept for actability is the performance of communicative actions, referred to as elementary actions (e-actions). The result of an e-action is an ae-message. As discussed above (Section 3.4), there are three kinds of such actions related to information systems: interactive, automatic and consequential.

Let us again consider the bookshop example introduced above. A user accessing the Web site and reading about the 'book of the month' would be performing an interactive action by purchasing the book, utilizing an order function provided by the Web-based information system. If the user, on the other hand, chose to print an order form and send it by traditional post, this would be a consequential action. Suppose also that the bookshop's information system collected all orders at the end of the day and sent a supplier order via Electronic Document Interchange (EDI) to a publisher containing all books ordered that day from that publisher; it would have performed an automatic action.

Based on this discussion, 'Actability' can be defined as: an information system's ability to perform actions, and to permit, promote and facilitate the performance of actions by users, both through the system and based on information from the system, in some business context. (cf. Cronholm et al., 1999).

\subsection{Information system usage situations}

When talking about the performance of actions in relation to information systems, and thus usage of the system, it is possible to distinguish three different types of IS usage situations:

1. An automatic usage situation occurs when an information system's 'ability to perform actions' is considered. That is, when an IS performs e-actions without any direct human intervention, but according to instructions by, and on commission of, some human actor. In these situations the IS is used as an automatic machine.

2. An interactive usage situation occurs when an IS is used to "permit, promote and facilitate the performance of actions by users ... through the system'. In these situations the IS is used as a 
mechanical tool.

3. A consequential usage situation occurs when an IS is used to 'permit, promote and facilitate the performance of actions by users ... based on information from the system'. In these situations the IS is used as a static tool.

In all three types of IS usage situations, there are three basic components involved: (1) the information system used by (2) an actor to perform (3) e-actions. These three entities participate together in a ternary relationship that forms the usage situation. To understand these components and how they interact within the ternary relation is the key to understanding actability.

To achieve such understanding it is necessary to comprehend the first component, information systems, as systems for communicative actions-that is, as information action systems. Thus, we define an 'information system' as: a technically implemented social system consisting of an action potential (a repertoire of actions and a vocabulary), a memory of earlier actions and action prerequisites, and actions performed interactively by the user and the system and/or automatically by the system. By using 'technically implemented social system' we adhere to the argument of Goldkuhl \& Lyytinen (1982) that information systems are not technological systems, but 'social systems only technically implemented'. To say that information systems have an 'action potential' means that any information system per se defines the set of actions that can be performed by using it. This also incorporates the vocabulary used to express communicative actions within it-how to refer to the state of affairs that is talked about. By 'memory of earlier actions and action prerequisites' we refer to the persistent storage aspect of information systems, which is updated and extended through the performance of e-actions. This is an important feature of information systems used to keep track of what has been said and done through the system and serves as important background for future actions. One can think of this action memory as a repository of messages held by the system. The action memory would typically be implemented as one or several databases, even though it might make use of whatever technological solution is available. In the bookshop example (see above), the action memory would typically be used to store, for example, order messages from customers in an order database. That would be an example of 'earlier messages'. It might, however, also contain information about what book that will be the book of the month during months to come, which then would constitute action prerequisites. The action memories of an organization's information systems form an important part of the overall organizational memory. It can be used to inform about who has done what with whom, when, and why. The 'actions performed ...' in the definition should be understood as the instance level of the system, whereas the 'action potential' represents the system's type level. It is important to include both levels in the definition since neither of them can be understood in isolation from the other. We use information systems to do things and to talk about the world, within the world. Information systems are not abstract models representing the state of the world, but parts of the world themselves.

Table 3 shows how different parts of an information system belong to these two levels. Note that the instance level consists of two different aspects. Messages represent the state of the system while actions represent a dynamic aspect.

The second component of an IS usage situation, the actor, relates to three different meta-roles: the communicator, the performer and the interpreter. The communicator is the human agent responsible for an e-action in relation to an interpreter (recipient). Sometimes the actual performance of an action is pursued by someone other than the communicator. This is most obvious in the case of automatic usage situations when the information system performs the action and thus plays the role of performer. However, sometimes another human agent performs an e-action interactively on commission of the communicator. This second human agent-acting as a mediator-then plays the role of performer. As indicated above, a human agent, using the system as an information provider for future actions outside the system (i.e., during a consequential usage situation), plays the role of interpreter. Human agents 
playing the latter two roles, i.e., performers and interpreters, are usually referred to as users within, for example, the human-computer interaction community. We would like to stress, however, that this notion of information systems usage is too restrictive. From an actability point-of-view, a communicator, as well as a performer or an interpreter, are users of the information system.

\begin{tabular}{|l|l|l|l|}
\hline Type level & $\begin{array}{l}\text { Action potential: rules for what actions to perform, } \\
\text { including what types of messages to treat }\end{array}$ & $\begin{array}{l}\text { Rules for action memory } \\
\text { (what types of messages to save } \\
\text { and the vocabulary used) }\end{array}$ \\
\hline Instance level & $\begin{array}{l}\text { Input, intermediate, } \\
\text { output messages } \\
\text { (state part) }\end{array}$ & $\begin{array}{l}\text { Performance of interactive and } \\
\text { automatic actions } \\
\text { (active part) }\end{array}$ & $\begin{array}{l}\text { Messages held in the action } \\
\text { memory } \\
\text { (state part) }\end{array}$ \\
\hline
\end{tabular}

Table 3: Description of an IT-based information system with respect to its type and instance levels.

The third part of an IS usage situation comprises the set of e-actions performed during the usage situation. This set consists of zero or more e-actions, possibly with associated sequence restrictions, that are logically grouped together to form a coherent whole. An interactive usage situation consists of one or several interactive, consequential, automatic and manual actions. It is defined as: all interactive actions, and intermediate consequential, automatic and manual actions, that are performed adjacent in time by the same performers (cf. Ågerfalk et al., 1999). A consequential usage situation consists of one or several consequential, automatic and manual actions. It is defined as: all consequential actions, and intermediate automatic and manual actions, that are performed adjacent in time by the same performers, which are not part of any interactive usage situation. Finally, the automatic usage situations of a system consist of one or several automatic actions and are defined as: all automatic actions that are performed adjacent in time by the same information system, that are not part of any interactive or consequential usage situation.

It is important to realize that consequential usage situations as well as interactive usage situations might incorporate human-computer interaction. In the latter case, the interaction aims at sending an e-message through the system. In the former, the aim is to interpret one or several e-messages in order to perform an action outside the system. It is also important to realize that interpreting earlier messages might also be an important part of an interactive usage situation. Hence, the two types of usage are tightly coupled, but are still distinguishable. Basically, from an information systems perspective, an interactive usage situation is a consequential usage situation with added complexity. The complexity is imposed by the functionality required to formulate and send messages, and to interpret the effects of the action. Since actions performed during consequential usage situations are always established outside the system, this aspect is not considered part of the IS, but might still be supported by it. What, then, do we mean by 'formulating messages'? The concept refers to the fact that before a communicative action can be performed, the speaker must formulate the sequence of words to utter (i.e., the preparation of the action). This includes formulating the propositional content of the action and attaching it to an understandable and appropriate action mode (i.e., the illocutionary meaning of the action) ${ }^{9}$. To interpret the effects of the action means to comprehend how the action changed the state of the social world in which it was performed (i.e., observing the perlocutionary effects, if possible). An important aspect of actability is that when e-actions are performed through an IS, these two cognitive tasks can be supported by the IS. A performer can, for example, interactively use the system to pick items from a list of merchandise in order to formulate an order message. It is worth noting that this makes the action preparation explicit as opposed to implicit during manual action.

\footnotetext{
${ }^{9}$ Note that this should not be mistaken for a rationalistic view on actions (cf. Section 3.1). Of course, people do not always consciously think through what to say in advance. However, perhaps they should, at least if what they are saying constitutes important business actions.
} 


\subsection{Elementary interactions}

The interactive formulation and sending of e-messages (and, if possible, the evaluation of their effects) is performed through elementary interactions (e-interactions). An e-interaction is an action at a lower level of abstraction than e-actions. An interacting user performs an e-interaction every time something is done with the interface of the system. Each e-interaction follows a recurring schema consisting of three phases: a user action, an IS action and an interpretation act. The user action represents the user's direct manipulation of objects on the computer screen, for example clicking a button labelled 'send'. The IS action represents the information system's response to the user action, for example sending whatever was to be sent. This phase might include several operations performed by the IS and usually ends with the system giving the user some sort of feedback. The interpretation act represents the user's effort to understand what the system achieved, by utilizing feedback from the system. We refer to this recurring schema as the elementary interaction loop (see Figure 4). Note that the loop might be recursively expanded since the interpretation act might require the performance of yet another e-interaction.

Both the formulation of e-messages and the execution of e-actions (i.e., sending of e-messages) are performed through e-interactions. The latter constitute a special case where the interpretation act includes the evaluation of the e-action as a whole. It is important that a system give as much feedback as possible about the effects of an e-action. However, because the effects might not be directly observable, the system should at least make the user aware that the e-action has been performed. Note that each e-interaction is 'triggered' by the interacting user.

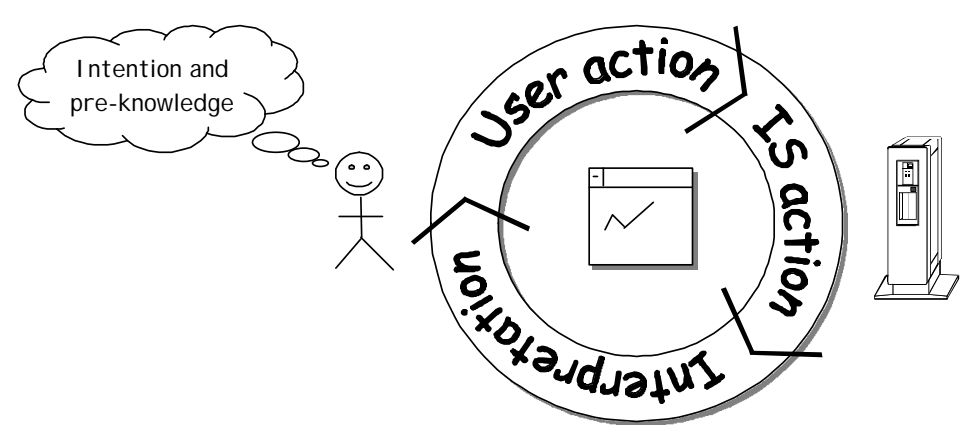

Figure 4: The elementary interaction loop. ${ }^{10}$

Before any e-interactions are performed, the IS might perform one or several initial IS actions to 'set the scene'. The IS might, for example display some initial information that the user can utilize when formulating a first e-message.

Figure 5 depicts the general structure of an interactive usage situation. Based on information provided by some initial IS actions ${ }^{11}$, the user formulates an e-message through a series of e-interactions. Finally the e-message is sent through the IS (an e-action is executed), causing a business effect. In each einteraction the user is given feedback from the IS. In the final e-interaction this includes information about the performed action and, if possible, its business effect(s).

Within our conceptualization of IS usage, actions take place at three different levels of abstraction. Eactions, e-interactions and the three phases of e-interactions represent these levels. In addition, we

\footnotetext{
${ }^{10}$ Adopted from Ågerfalk et al. (1999).

11 Note that these are optional, as there are interactive usage situations where no initial IS actions are performed.
} 
introduced the concept of initial IS actions above. Figure 6 depicts a JSP diagram showing the structure of an interactive usage situation to illustrate how these components relate.

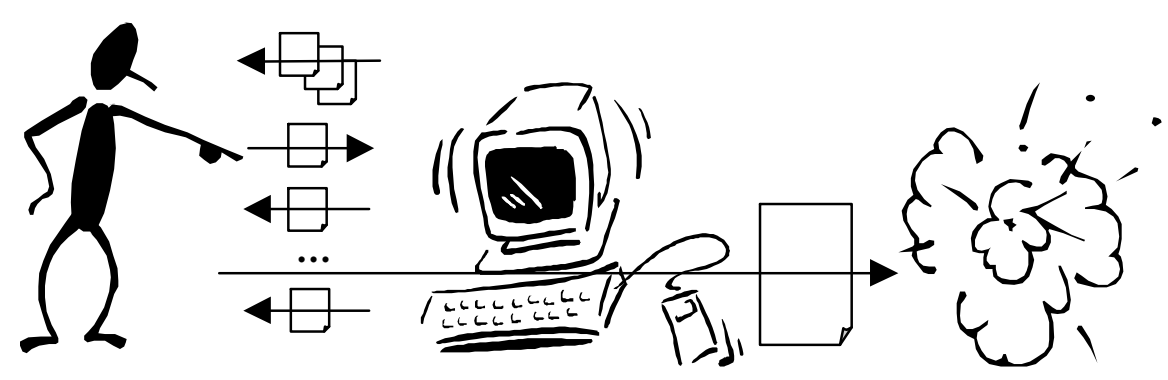

Figure 5: An e-message is formulated and sent by an interacting user during an interactive usage situation. ${ }^{12}$

From the JSP diagram we see how an interactive usage situation is initialized by a series of zero or more initial IS actions, followed by zero or more e-actions. For each e-action there is a 'preparation phase' during which the e-action is formulated (cf. Section 3.1). This is done through zero or more einteractions, each consisting of a user action, an IS action (which might in fact consist of several operations) and an interpretation act. When the formulation is complete the user enters the "execution phase' and can choose to execute the e-action by performing yet another e-interaction. During this 'final' e-interaction the interpretation act includes the evaluation of the complete e-action. Hence, it constitutes the 'evaluation phase' as well. It is important to note that the user can choose to abandon the current e-action provided the 'final' e-interaction has not yet been initiated. After that, it cannot be cancelled.

Let us return to the virtual bookshop example introduced in Section 3.4. The bookshop is, via their Web site, offering a 'book of the month' for a special price. By following a link on their home page, a new page is opened and shows the 'book of the month offer' in the frame dedicated to show details of books. A customer (i.e., an interacting user) can choose to click on a button labelled 'add to shopping cart' and then click on another button to go to the 'cashier'. Now the user must provide the system with identification information. This is achieved by clicking on either the button labelled 'log in' if already registered, or on the button labelled 'new customer'. Assuming this is an old customer, when logged on, shipping details are shown in an order document, which also contains information about the book that was put in the shopping cart earlier. To go through with the purchase, the user must now click on the button labelled 'send order'. A new page is then shown, telling the user that the order is being processed and that the book should be delivered within four days if nothing unusual happens.

In the example, every single click on the different buttons constitutes an e-interaction. The message being sent from the customer to the bookshop is an order. The action mode of this order contains two different illocutions. The first is a request to the bookshop to deliver the book in question. The second is a promise to the bookshop that the agreed price will be paid when the book is received ${ }^{13}$. The order emessage is sent by the 'final' e-interaction performed by clicking on the 'send order' button. For every e-interaction, the system responded by displaying a different page-helping the user to interpret the actions. Note that the formulation of the order message was initiated as soon as the user added the book to the shopping cart, as the system used this information to give an order proposal. When the user first entered the bookshop site, the 'book of the month' offer was shown. This is an example of an initial IS

\footnotetext{
${ }^{12}$ Adopted from Ågerfalk et al. (1999).

${ }^{13}$ In reality this means of payment is probably rare. Most Web sites require credit details up front, so that in fact the bank promises to pay on behalf of the customer at the time of purchase, not the time of delivery.
} 
action. Note that the user could have withdrawn the purchase free of obligations, until the moment the 'send order' button was clicked. After that the user will (probably) be legally bound to pay for the ordered book.

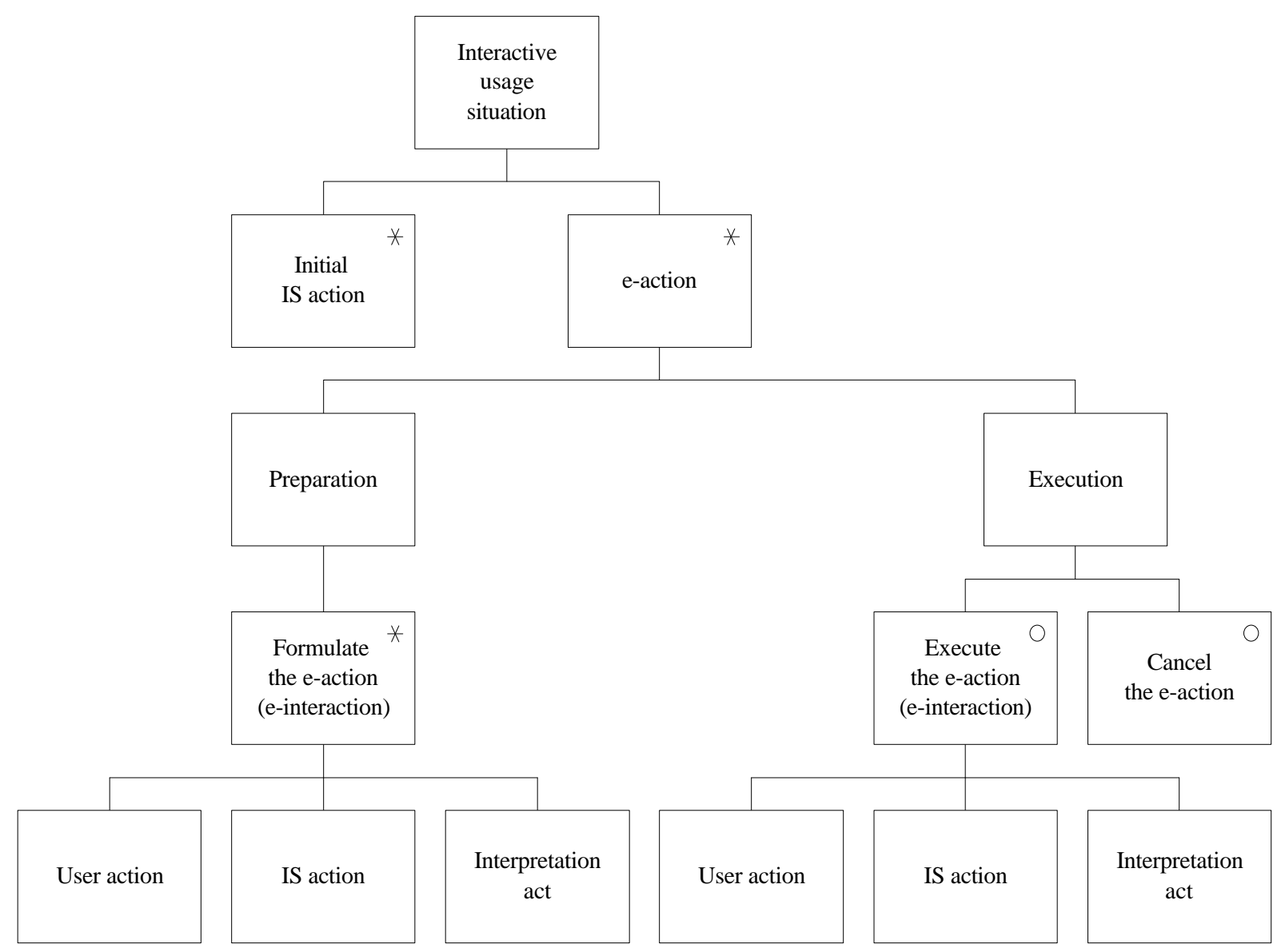

Figure 6: JSP diagram showing the action structure of interactive usage situations.

E-messages can be carried by, and visualized as, documents. We use 'document' as a generic concept referring to 'traditional' paper documents as well as screen documents (e.g., forms, dialogues and windows) and, for example, EDI documents. An interactive screen document is used to interactively manipulate the IS and serves as an action medium in the communication through the IS. In the bookshop example above, every Web page except for the last is an interactive screen document. The last page was a static screen document used only to mediate the order acknowledgment to the customer ${ }^{14}$.

The actability way of understanding IS usage is influenced by, and should therefore be related to, the 'seven stages of action' model of Norman (1988) as described in Section 3.1. Since e-actions and einteractions are both actions, but at different levels of abstraction, they can both be related to the model, as shown in Table 4.

As Table 4 indicates, Norman's model has been extended with an additional stage 4.5 to show the IS action performed within an interaction loop. It is also during this stage that the possible consequences of the action arise.

\footnotetext{
${ }^{14}$ That is, assuming that no action potential was made available by the page. It might very well have been, for example, a button labelled 'print page'. In that case, it would have been an interactive screen document.
} 


\begin{tabular}{|c|c|c|c|c|c|}
\hline \multicolumn{2}{|c|}{ Stage } & Norman & e-actions & \multicolumn{2}{|c|}{ e-interactions } \\
\hline 1 & \multirow{3}{*}{$\begin{array}{l}\mathrm{P} \\
\mathrm{r} \\
\mathrm{e} \\
\mathrm{p} .\end{array}$} & Forming the goal & $\begin{array}{l}\text { Deciding desired } \\
\text { perlocutionary effect(s) }\end{array}$ & \multirow{4}{*}{$\begin{array}{ll}\mathrm{U} & \mathrm{A} \\
\mathrm{s} & \mathrm{c} \\
\mathrm{e} & \mathrm{t} \\
\mathrm{r} & \mathrm{i} \\
& \mathrm{o} \\
& \mathrm{n}\end{array}$} & Forming the goal \\
\hline 2 & & Forming the intention & Choosing action mode & & Choosing User action \\
\hline 3 & & Specifying the action & Formulating the ae-message & & Specifying the User action. \\
\hline 4 & \multirow{2}{*}{$\begin{array}{l}\mathrm{E} \\
\mathrm{x} \\
\mathrm{e} .\end{array}$} & Executing the action & Executing the e-action & & Performing the User action \\
\hline 4.5 & & & Consequences arise & & IS action performed \\
\hline 5 & \multirow{3}{*}{$\begin{array}{l}\text { E } \\
\mathrm{v} \\
\mathrm{a} \\
\mathrm{l} \\
\mathrm{u} \\
\mathrm{a} .\end{array}$} & $\begin{array}{l}\text { Perceiving the system } \\
\text { state }\end{array}$ & Perceiving the business state & \multirow{3}{*}{$\begin{array}{ll}\mathrm{I} & \mathrm{a} \\
\mathrm{n} & \mathrm{c} \\
\mathrm{t} & \mathrm{t} \\
\mathrm{e} & \\
\mathrm{r} & \\
\mathrm{p} . & \end{array}$} & Perceiving the system's response \\
\hline 6 & & $\begin{array}{l}\text { Interpreting the } \\
\text { system state }\end{array}$ & $\begin{array}{l}\text { Interpreting the business } \\
\text { state }\end{array}$ & & Performing the interpretation act \\
\hline 7 & & $\begin{array}{l}\text { Evaluating the } \\
\text { outcome }\end{array}$ & $\begin{array}{l}\text { Evaluating the performed } \\
\text { action and the IS }\end{array}$ & & $\begin{array}{l}\text { Evaluating what the system has } \\
\text { achieved }\end{array}$ \\
\hline
\end{tabular}

Table 4: Norman's (1988) 'seven stages of action' model compared with execution of e-actions and formulation of ae-messages by e-interactions. ${ }^{15}$

In the above discussion, we have focused on interactive usage situations. If a consequential usage situation includes interactive usage of an IS, many of the same characteristics apply, i.e., interactions with the IS follow the structure of the elementary interaction loop. What differs is that the formulation is done implicitly with the support of the system instead of explicitly in an interactive screen document. Furthermore, the execution and evaluation phases are performed without using the system, i.e., manually. It is important to understand that not every consequential usage situation includes interactive usage of an IS. Instead, paper documents are often used as carriers of messages in these situations.

\subsection{Actability features of information systems}

From the above we can conclude that in order for an IS to be regarded as actable during an interactive usage situation it should be able to help (permit, promote and facilitate) an interacting performer to:

1. choose what communicative action to perform (at action level);

2. formulate the propositional content of the action and attach it to an understandable and appropriate action mode (at interaction level); and

3. execute the communicative action; and finally to

4. interpret and evaluate the action and its business effect(s).

Furthermore, the IS should be able to help (permit, promote and facilitate) an interpreter to acquire sufficient background to perform the intended action during a consequential usage situation.

Finally, the IS should be able to make the communicator feel confident that the performer (human or automaton) really performs the intended action and that the resulting message reaches the intended interpreter(s).

Any usage situation must be understood within the context of doing business with some other party. In a business setting, the interpreter (recipient) of a 'business message' (ae-message) must trust what is said (and thus communicatively done) by a speaker (communicator). To understand the meaning of 'trust what is said' we turn to the 'universal validity claims' proposed by Habermas (1984). He argues that such claims are raised by any communicator and presupposed by the communicator to be accepted by the interpreter. Successful communication implies that the listener must both comprehend the action and accept it as valid. That is, the communicator and the interpreter must agree on the communicative act in

${ }^{15}$ Adopted and modified from Ågerfalk (1999). 
order for it to be successful. To reach such mutual understanding a communicator raises four universal validity claims (ibid.): (1) a claim of comprehensibility, (2) a claim of truth, (3) a claim of rightness, and (4) a claim of sincerity.

The first claim, (1) the claim of comprehensibility, means that a communicator must be able to formulate a grammatically correct, comprehensible sentence. In the context of the bookshop example above this means, for example, that the 'book of the month' on-line offer must be expressed in a way understandable by potential customers. This can be achieved in several different ways, for example by conforming to accepted standards, protocols and user interface design guidelines. This relates to the 'permit, promote and facilitate' in the definition of actability (see above). It is, for example, possible to talk about action visibility of an IS when its action potential is 'self-explanatory', i.e., easy to understand and use (cf. Norman (1988) on the concepts of 'affordance' and 'visibility'). The second claim, (2) the claim of truth, means that an action must refer to the true state of affairs. In the on-line offer example, this would, for example, imply that there actually are books to be delivered as expressed in the offer and that these books are correctly described. The third claim, (3) the claim of rightness, means that a communicator must be able to establish an interpersonal relationship in the right way according to accepted social norms. For example, the bookshop must be able to act according to applicable legal and cultural norms of trade. The fourth claim, (4) the claim of sincerity, means that a communicator must have sincere intentions, for example, that the bookshop actually intends to sell its books to a visitor.

From this we can conclude that if an IS is to be regarded as actable its users must be able to both comprehend it syntactically and semantically and accept its underlying intentions as true, sincere and correct.

\section{Implications for Information Systems Design}

Adhering to the concept of actability has important implications for the way information systems are designed. It implies a shift from the traditional focus on data structures (i.e., syntactic and semantic aspects) to take the systems, actors and their actions as the point of departure for design. It is by understanding the structure of an organization's actions and hence its communication patterns that it becomes possible to design actable information systems. This also means a shift from focusing on the functions of organizations and information systems. The action structures of an organization form its business processes. Thus, it is not adequate to talk about business functions that require an information system to have various functionalities for it to be effective and efficient. Instead, information systems design should focus on what the actors do (communicative and material actions) to create value for the organization's clients. Designing an IS then implies designing its action potential so that it matches the requirements of its users. Designing for actability is a holistic approach where the value-creating activities of an organization as a whole are considered - there is no point in designing information systems isolated from their action context.

From our work with methods to support actability-oriented requirements engineering (e.g., Ågerfalk, 1999) we have extracted two principles that we believe are crucial for the design of actable information systems: (1) focus on actions and (2) integrate early prototyping with visual modelling.

To (1) focus on actions means to use the concepts of e-action and ae-message as a foundation for understanding the role and tasks of developed information systems and for partitioning the development work into manageable pieces. When designing the action structures of business processes, the performance of actions is allocated to human actors and information systems. From this model, it is straightforward to partition the usage of information systems into usage situations: interactive, automatic and consequential. Each usage situation can then be analysed in terms of what e-actions are performed and what IS support is required to perform them in terms of interactions, interaction 
sequence restrictions and concepts used to express them. To focus on actions means to always keep the definition of actability in mind and think of how to design, so as to permit, promote and facilitate action by and through the system. One benefit of focusing on actions is that requirements become traceable throughout the different models created during systems development: from business models, through interaction models, and down to detailed requirements on system operations (Ågerfalk, 1999). To focus on actions is also important in understanding responsibilities within an organization. Who says what to whom, when, and why. Identifying the communicators and stressing that they are users even though they may never touch the system physically, helps to shift the question of 'system ownership' into 'action responsibility', which is much more tangible for the persons involved.

(2) Early prototyping means creating examples of the user interface early in the development process. The user interface is the visual part of the IS with which interacting users communicate. Exploring different alternatives together with the users is essential to design the visual layout of the system. Additionally, it is an invaluable tool to understand the professional language of the users and hence an important input to conceptual modelling. Our research has also shown (Ågerfalk, 1999) that creating prototypes helps, not only in getting the system right, but also in gaining an understanding of how the business will actually be performed. Hence, user interface prototyping is an important input to business modelling as well. By visual modelling, we refer to analytical descriptions of a system in some defined notation (e.g., class diagrams and data flow diagrams). Visual models are important for promoting communication about a system at different levels of abstraction. To understand a system under construction, developers should both exemplify (with prototypes) and analytically abstract (with visual models). These two approaches can be integrated to utilize the strengths of both (cf. Mathiassen et al., 1995). Prototypes are important, for example, to discuss interactive screen documents with users in order to gain knowledge important to creating the visual models. On the other hand, visual models can serve as important 'road maps' to help users focus on different parts of the system when the prototypes are being created (Ågerfalk, 1999).

\section{Conclusions}

There is an urgent need to create a deeper understanding of information systems in organizational settings. Information systems are technically implemented, but they cannot be understood as mere technical objects. Their special character is that they are formalized sign systems and as such are used for human communication. A semiotic perspective, emphasizing the sign and communication character of information systems, is necessary when establishing an organizational theory of information systems. In this chapter we have investigated different aspects of information systems from a semiotic standpoint with emphasis on the top stages of the semiotic ladder (Stamper, 1994) - the social and pragmatic aspects. A key concept for such an understanding of social and pragmatic aspects of information systems has been presented: information systems actability. Standing on the top of the ladder, we have also discussed some matters concerning meaning, structure and media.

We have identified two different types of actions related to signs:

- Action within the sign transfer

- Action based on the transferred sign

These two types of actions can be related to our conceptualization of information systems actability and the three types of IS usage situations. Action within sign transfer is what is performed during interactive and automatic usage situations. Action based on the transferred sign is what is performed during consequential usage situations and sometimes during interactive usage situations.

We have also analysed the role of messages (sign constellations) within information systems. In our analysis we have used speech act theory as our main source of inspiration. This has led us to the concept of ae-messages consisting of an action mode (type of illocution) and a propositional content. 
Ae-messages are results of communicative actions that we call e-actions. Input and output messages of information systems are realized through documents. Interactive screen documents play a special role: not only are they a result of action, they are also used in interactive usage situations for several purposes. Such a document can aid the user to formulate the ae-message (the propositional content) and attach it to an appropriate action mode. In addition, it is also an action medium for the execution of the e-action.

We claim information systems actability to be an important conceptualization for understanding the use of information systems in organizations. It makes it possible - within one theoretical framework - to relate different aspects (such as technical, cognitive, behavioural, linguistic and organizational) to each other. This is possible because of our basic pragmatic perspective. Starting from human action, we have given a coherent description of social action, organizational action and artefacts usage as a basis for formulating the concept of information systems actability.

\section{References}

Ågerfalk, P. J. (1999). Pragmatization of Information Systems - A Theoretical and Methodological Outline, Licentiate thesis, IDA, Linköping University, Sweden.

Ågerfalk, P. J., Goldkuhl, G. and Cronholm, S. (1999). Information Systems Actability Engineering: Integrating Analysis of Business Processes and Usability Requirements. In Proceedings, $4^{\text {th }}$ International Workshop on the Language Action Perspective on Communication Modelling (LAP'99), pp.73-86, Copenhagen, Denmark, September 12-13, 1999.

Ahrne, G. (1994). Social organizations. Interaction inside, outside and between organizations, Sage, London.

Austin, J. L. (1962). How to do things with words, Oxford University Press, Cambridge.

Berger, P. L. and Luckmann, T. (1967) The social construction of reality, Doubleday \& Co, Garden City.

Cronholm, S., Ågerfalk, P. J. and Goldkuhl, G. (1999). From Usability to Actability. In Proceedings, 8th Intl. Conference on Human-Computer Interaction (HCI International '99), Munich, August 22-27, 1999.

Dietz, J. L. G. (1994). Business modelling for business redesign, in Proc. 27th Annual Hawaii Intl. Conference on Systems Science, IEEE.

Giddens, A. (1984). The constitution of society. Outline of the theory of structuration, Polity Press, Cambridge.

Goldkuhl, G. (1995). Information as action and communication. In Dahlbom, B. (Ed., 1995) The infological equation. Essays in honor of Börje Langefors, Gothenburg Studies in Information Systems 6, Göteborg University.

Goldkuhl, G. (1996). Generic business frameworks and action modelling, In Proceedings Communication modelling - Language/Action Perspective'96, Springer Verlag. 
Goldkuhl, G. (1998a). Handlingars vad, vem och var. Ett praktikteoretiskt bidrag, (in Swedish), Working paper, CMTO, Linköping University.

Goldkuhl, G. (1998b). Towards an action oriented understanding of organizational change, Working paper, CMTO, Linköping University.

Goldkuhl, G. and Ågerfalk, P. J. (1998). Action within Information Systems: Outline of a Requirements Engineering Method. In Proceedings $4^{\text {th }}$ International Workshop on Requirements Engineering: Foundation for Software Quality (REFSQ’98). Pisa, Italy, June 8-9, 1998.

Goldkuhl, G. and Lyytinen, K. (1982). A language action view of information systems. In Proceedings 3rd International Conference on Information Systems, Ann Arbor.

Goldkuhl, G. and Nilsson, E. (2000). Organisational Ability - constituents and congruencies. Accepted for OR42, Swansea, Wales

Goldkuhl, G. and Röstlinger, A. (1999). Expanding the scope: From language action to generic practice. In Proceedings $4^{\text {th }}$ International Workshop on the Language Action Perspective on Communication Modelling (LAP'99). Copenhagen, Denmark, September 12-13, 1999.

Habermas, J. (1984). The theory of communicative action 1. Reason and the rationalization of society, Polity Press, Cambridge.

Joas, H. (1993). Pragmatism and social theory, University of Chicago Press, Chicago.

Langefors, B. (1966). Theoretical analysis of information systems, Studentlitteratur, Lund.

Langefors, B. (1995). Essays on Infology. Dahlbom B. (ed.), Studentlitteratur, Lund, Sweden.

Latour, B. (1992). Technology is society made durable, in Law (ed., 1992), A sociology of monsters: essays on power, technology and domination, Routledge\& Kegan Paul, London.

Liu, K., Stamper, R., Clarke, R. and Andersen, P. (eds., 2000). Organisational Semiotics, Kluwer Academic Press (in press).

Mathiassen, L., Seewaldt, T. and Stage, J. (1995). Prototyping and Specifying: Principles and Practices of a Mixed Approach. Scandinavian Journal of Information Systems, Vol. 7, No. 1.

Norman, D. A. (1988). The psychology of everyday things, Basic Books, New York.

Preece, J., Rogers, Y., Sharp, H., Benyon, D., Holland, S. and Carey, T. (1994). Human-computerinteraction, Addison-Wesley.

Scott, W. R. (1995). Institutions and organizations, Sage, Thousand Oaks.

Searle, J. R. (1969). Speech acts. An essay in the philosophy of language, Cambridge University Press, London.

Stamper, R. K. (1994). Signs, information, norms and systems, in Holmqvist, B., Andersen, P. B., Klein, H. and Posner, R. (eds., 1994), Signs at work, De Gruyter, Berlin. 
Stamper, R. (2000). Informatics without the Computer. In Liu, K., Stamper, R., Clarke, R. and Andersen, P. (eds., 2000). Organisational Semiotics, Kluwer Academic Press (in press).

Thayer, H. S. (1981). Meaning and action. A critical history of pragmatism, Hackett Publishing, Indianapolis.

Weber, M. (1978). Economy and society, University of California Press, Berkeley.

Weizenbaum, J. (1976). Computer power and human reason, Freeman, San Francisco.

Winograd, T. and Flores, F (1986). Understanding computers and cognition: A new foundation for design, Ablex, Norwood. 